Original article

\title{
Incidence of COVID-19 among returning travelers in quarantine facilities: A longitudinal study and lessons learned
}

\author{
Jaffar A. Al-Tawfiq a,b,c,*, Amar Sattar ${ }^{\text {d }}$, Husain Al-Khadra ${ }^{\text {d, Saeed Al-Qahtani }}{ }^{\text {d, }}$ \\ Mobarak Al-Mulhim ${ }^{\mathrm{e}}$, Omar Al-Omoush ${ }^{\mathrm{d}}$, Hatim O. Kheir ${ }^{\mathrm{d}}$ \\ a Specialty Internal Medicine and Quality Department, Johns Hopkins Aramco Healthcare, Dhahran, Saudi Arabia \\ ${ }^{\mathrm{b}}$ Infectious Disease Division, Department of Medicine, Indiana University School of Medicine, Indianapolis, IN, USA \\ ${ }^{\mathrm{c}}$ Infectious Disease Division, Department of Medicine, Johns Hopkins University School of Medicine, Baltimore, MD, USA \\ ${ }^{\mathrm{d}}$ Primary Care Division, Johns Hopkins Aramco Healthcare, Dhahran, Saudi Arabia \\ ${ }^{\mathrm{e}}$ King Fahd Specialist Hospital Dammam, Saudi Arabia
}

\section{A R T I C L E I N F O}

\section{Keywords:}

SARS-CoV-2

COVID-19

Quarantine

Travelers

\begin{abstract}
A B S T R A C T
Introduction: The emergence of the Severe Acute Respiratory Syndrome Coronavirus 2 (SARS-CoV-2) had resulted in an unpresented global pandemic. In the initial events, the Kingdom of Saudi Arabia implemented mandatory quarantine of returning travelers in order to contain COVID-19 cases.

Materials and methods: This is a longitudinal study of the arriving travelers to Quarantine facilities and the prevalence of positive SARS-CoV-2 as detected by RT-PCR.

Results: During the study period, there was a total of 1928 returning travelers with $1273(66 \%)$ males. The age range was 28 days-69 years. Of all the travelers, $23(1.2 \%)$ tested positive for SARS-CoV-2. Of the first swab, 14/ $1928(0.7 \%)$ tested positive. The positivity rate was $0.63 \%$ and $0.92 \%$ among males and females, respectively (P $=0.57)$. The second swab was positive in $9(0.5 \%)$ of the other 1914 who were initially negative with a positivity rate of $0.39 \%$ and $0.62 \%$ among males and females, respectively $(\mathrm{P}=0.49)$. There was no statistical difference in the positivity rates between first and second swab $(P=0.4)$. Of all travelers, $40(n=26,1.3 \%)$ were admitted from the quarantine facility to the hospital due to COVID-19 related positive results or development of symptoms such as fever, cough, and respiratory symptoms; and $14(0.7 \%)$ were admitted due to non-COVID-19 related illness.

Conclusion: This study showed the efforts put for facility quarantine and that such activity yielded a lower incidence of positive cases. There was a need to have a backup healthcare facility to accommodate those developing a medical need for evaluation and admission for non-COVID-19 related illnesses.
\end{abstract}

\section{Introduction}

The emergence of the Severe Acute Respiratory Syndrome Coronavirus 2 (SARS-CoV-2) had resulted in an unpresented global pandemic. SARS-CoV-2, the causative agent of the Coronavirus Disease 2019 (COVID-19) had been associated with asymptomatic infection [1]. Initial reported cases of COVID-19 in the Gulf region were among travelers who came from Iran and Iraq to Bahrain and Kuwait. The first case of the COVID-19 infection in Saudi Arabia was in Qatif city, in the Eastern province and was reported in a person who came from Iran [2, 3]. The case was reported on March 2nd, 2020 and 51 contacts tested negative for SARS-CoV-2 [3]. The Kingdom of Saudi Arabia had taken extensive preemptive strategies to curtain the development of COVID-19 [3-5]. As initial cases being reported in KSA, there were multiple interventions to control the spread of the virus and included: cancellation of events with the potential for a superspreading events such as mass gathering events, citywide festivals, religious gatherings, cultural celebrations and scientific conferences [3]. On 27 February 2020, visits to Makkah for the mini-pilgrimage (Umrah) was suspended [6]. In addition, there was curfew implementation in various cities with time being adjusted to the number of reported cases [3]. It is important to point out that the first case of COVID-19 in KSA was announced on March 2nd,

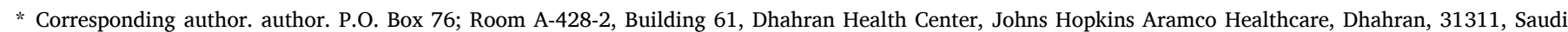
Arabia.

E-mail addresses: jaffar.tawfiq@jhah.com, jaltawfi@yahoo.com (J.A. Al-Tawfiq).
} 
2020 in a citizen returning from Iran in the Qatif region, Eastern KSA, and 51 contacts tested negative [3]. Subsequently, the cumulative numbers of cases were 104 on March 14, 7142 on April 14, 54752 on May 17, and 335578 on October 2, 2020.

All international flights were suspended on March 15, 2020 and all returning travelers were required to have a two-week quarantine in dedicated quarantine facilities. Quarantine is one of the methods to control the spread of emerging infectious diseases and is the process of separating or restricting movement of exposed non-infected individuals for the duration of the incubation period [7]. The word "quarantine" originates from the Latin "quadragina" or the Italian "quaranta", meaning 40 and refers to sailors who were observed for 40 days before disembarkation ships during the bubonic and pneumonic plague [8]. Governmental quarantine facilities were utilized during the SARS outbreak and individuals needing quarantine were hosted in individual rooms and meals were provided to them [8]. In Hong Kong, 131132 persons (50319 close contacts and 80813 travelers) were placed in quarantine [8]. The process of quarantine was also used for exposed healthcare workers during MERS-CoV and SARS $[9,10]$. The Kingdom of Saudi Arabia implemented flight restrictions in order to contain the spread of SARS-CoV-2. Passengers arriving on March 6th, 2020 forward and were coming from high-risk countries had been placed in mandatory Government Quarantine facilities. Johns Hopkins Aramco Healthcare (JHAH), a fully integrated health system which provides medical coverage to the employees of Saudi Aramco, the world's largest Energy Company, elected to run Quarantine facilities for its returning employees. JHAH was responsible for a total of 7 Quarantine facilities between March 14th and June 7, 2020. These were a combination of International Chain hotels and Saudi Aramco owned Apartments. Here, we present this experience and calculate the incidence of travel-associated COVID-19 infection among returning travelers.

\section{Materials and Methods}

Saudi Aramco had a sizeable population outside the Kingdom of Saudi Arabia at the time of Travel restrictions. These included employees working on Joint Ventures, attending conferences and business meetings and both Undergraduate and Postgraduate Students. Employees on long term assignments were also accompanied with their families. There were additionally patients who were abroad receiving medical treatment.

Johns Hopkins Aramco Healthcare (JHAH) established in coordination with the Saudi Ministry of Health (MOH) quarantine facilities to host returning travelers. The quarantine facilities required extensive multidisciplinary efforts (Fig. 1). JHAH provided the provision of 24-h coverage and administrative support to these facilities. There were over 140 staff involved including physicians, nurses and administration (Fig. 1).

There were cyclical peaks of resources needed to manage the workflow. The peaks of the work were at admission, swabbing and discharge (Fig. 2). There were multiple admission dates and thus there were multiple stages of the cycle simultaneously occurring. The first batch of travelers $(\mathrm{n}=118)$ arrived at the Quarantine facilities on March 14,2020 . However, these travelers had already been in the Kingdom in Government operated Quarantine facilities with a varying stay from 1 to 6 days in duration. All travelers from 14th March 2020 onwards came directly to the JHAH Quarantine facilities (Fig. 3). Prior to the opening of these facilities, there were thorough assessments of the sites coupled

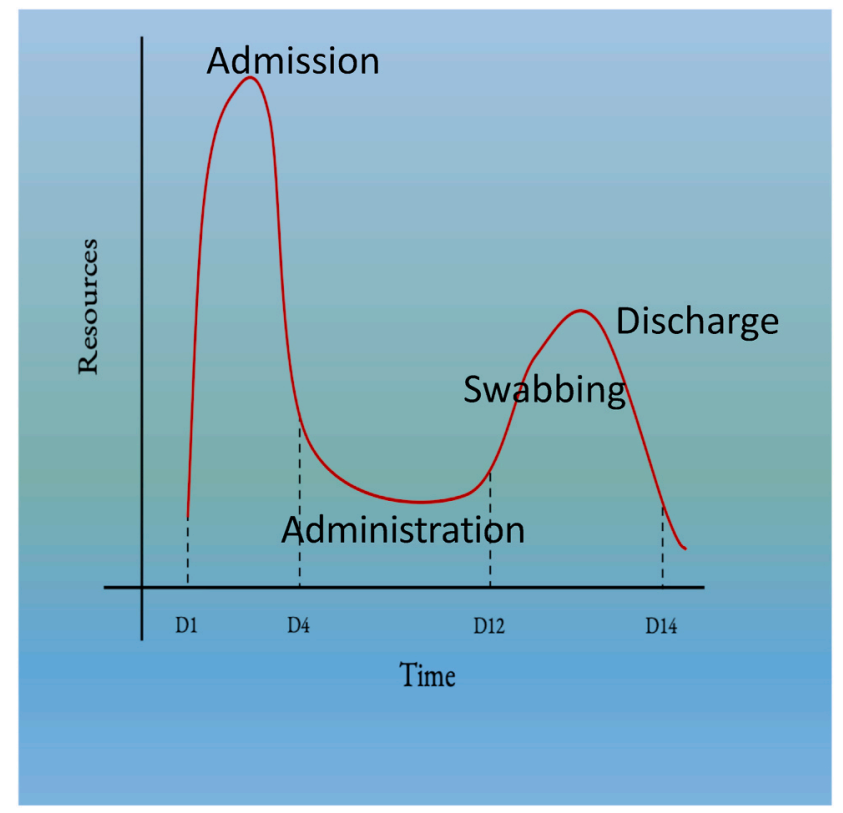

Fig. 2. A diagram showing the cyclical peaks of needed resources at the Quarantine Facilities. The X-axis shows the days of Quarantine.

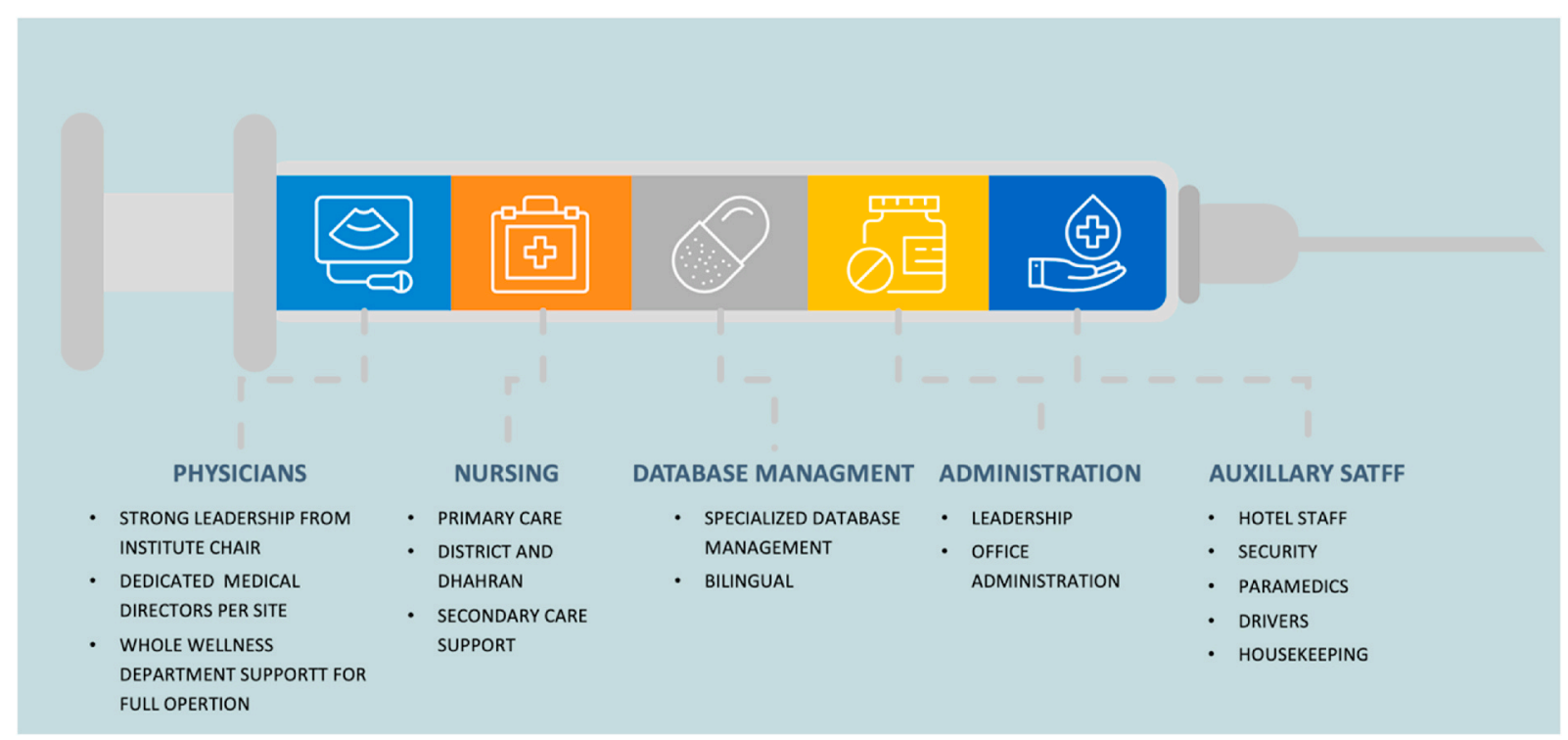

Fig. 1. A diagram showing the different multidisciplinary Efforts in the Quarantine Facilities. 


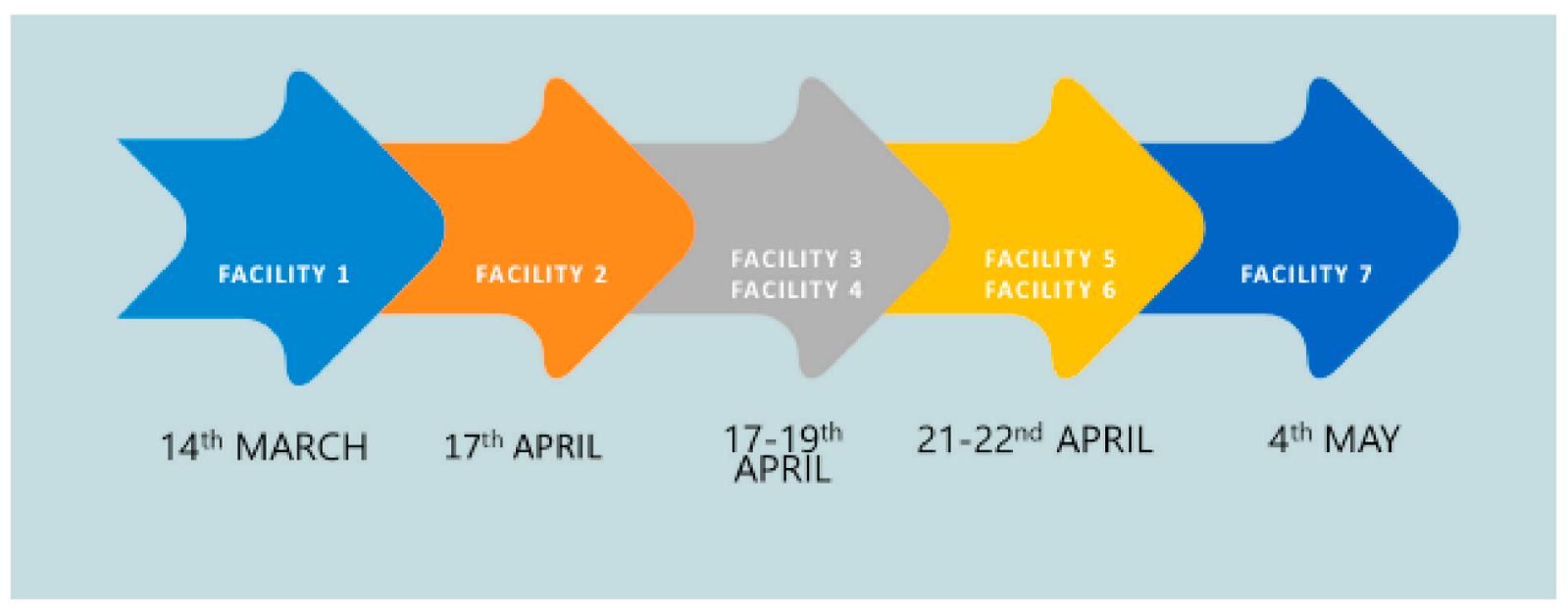

Fig. 3. Timeline of Arriving Travelers into the Quarantine Facilities.

with ensuring the availability of medical staff in each facility. Infection control teams visited these sites and intensive education was conducted for all medical staff and for housekeeping personnel on waste disposal.

A small number of the returning travelers were repatriated to Saudi Arabia in the last Scheduled flights returning before the travel ban came into effect. All of those travelers arrived from high risk countries such as Italy, Spain and the USA. The arriving travelers were predominantly employees returning from Europe and the others were students and those who were abroad for medical treatments. All those travelers were subject to a mandatory two-week quarantine with the requirement of nasopharyngeal and oropharyngeal swab at the beginning of arrival and before the conclusion of the quarantine period. Travelers arriving after May 7th, 2020 were allowed to complete one week of facility quarantine followed by an additional week of home quarantine, monitored by Mobile phone tracking to ensure compliance.

Travelers arrived from USA, United Kingdom, Spain, Italy, Canada, Egypt, Dubai, Oman and Bahrain. Those that came from Bahrain had originally come from other parts of the world but were transiting through Bahrain. They had not been allowed to travel onwards and were subject to 2 weeks of government Quarantine in Bahrain before arriving in Saudi Arabia by buses, ensuring universal masking and social distancing, through the King Fahad causeway (joining Bahrain and Saudi Arabia). All other travelers had arrived by airplane and were brought from the airport directly to the facility utilizing specifically designated buses fulfilling the requirement of social distancing and universal masking.

The day of Arrival was considered as Day " 0 " of the clinical course. Each arriving traveler was visually triaged for fever and other respiratory symptoms. Those who reported any such symptoms were admitted to the hospital for further observation and management. Those who had no symptoms on screening were checked into individual rooms and had both Nasopharyngeal and Oropharyngeal swabs testing for SARS-CoV2within $24 \mathrm{~h}$ of arrival for COVID 19.

There were strict Quarantine protocols, with guest not being allowed out of their rooms except in case of an emergency. Guests were monitored twice a day for temperature and the development of any respiratory symptoms. If any guest developed symptoms then the guest was transferred to hospital for management and retesting. The guest would remain in the hospital until symptoms resolve and there is a negative PCR test for SARS-CoV-2 and then he/she was sent back to the quarantine facility. If the SARS-CoV-2 PCR test turned to be positive, the guest was transferred to JHAH Hospital. The Quarantine facility had 24 $\mathrm{h}$ medical coverage from a multidisciplinary team. They were able to address all COVID-19 and non-COVID-19 related medical issues.

Travelers were retested pre-discharge by repeating the swab on day 12 or day 13 of their stay. If the results were negative, they were discharged on Day 14 from the Quarantine facilities back into the community. If they tested positive, they were admitted to JHAH hospital.

The diagnosis of SARS-CoV-2 infection was based on real-time reverse-transcriptase-polymerase-chain-reaction (RT-PCR) assay as described previously $[2,11]$. We analyzed the presentation and incidence of COVID-19. We also collected the demographic, age, gender, country and date of arrival to the Kingdom and SARS-CoV-2 RT-PCR results for all 1928 travelers.

\section{Results}

During the study period, there was a total of 1928 returning travelers with 1273 (66\%) males. The age range was 28 days-69 years and the highest number $1020(52.9 \%)$ were $20-29$ years of age (Fig. 4 and Table 1). Of the travelers, $23(1.2 \%)$ tested positive. Of the first swab, $14 / 1928(0.7 \%)$ tested positive. The positivity rate was $0.63 \%$ and $0.92 \%$ among males and females, respectively $(P=0.57)$ (Fig. 5). The second swab was positive in $9(0.5 \%)$ of the other 1914 who were initially negative with a positivity rate of $0.39 \%$ and $0.62 \%$ among males and females, respectively $(P=0.49)$. There was no statistical difference in the positivity rates between first and second swab $(P=0.4)$. Table 2 shows the incidence rate (\%) of positive samples according to the age range (in years). The Quarantine activity satrted on March $6^{\text {th }}, 2020$ and in the $1^{\text {st }}$ four weeks of the Quarantine the prevalence of COVID-19 positivity was $5.9 \%$ (Table 3). After that, the incidence steady declined and no further new cases were detected after the eighth week. On the other hand, the prevalence of positive SARS-CoV-2 cases decreased overtime due to increasing number of guests and lower incidence of travel-associated cases (Table 3).

The country of origin of positive 1st swab was predominantly among those returning from the United Kingdom $(11 / 14,79 \%)$ then those from Bahrain $(2 / 14,14 \%)$ and $7 \%(1 / 14)$ from USA. Travelers from Bahrain had spent a minimum of 2 weeks of Quarantine in Bahrain after arriving from the UK and USA. They were considered as having originated from Bahrain for this reason. The two cases that tested positive after arriving from Bahrain had both originated from the UK, giving UK 93\% of all positive travelers.

Of all travelers, $40(n=26,1.3 \%)$ were admitted from the quarantine to the hospital due to COVID-19 related positive results or development of symptoms such as fever, cough, and respiratory symptoms (Table 1). In addition, $14(0.7 \%)$ were admitted due to non-COVID-19 related illness such as diabetic ketoacidosis (new onset type 1 diabetes mellitus), appendicitis, fracture, dental abscess, neonatal sepsis, sickle cell vasoocclusive crisis, thrombosed piles, anxiety attack, depression, vasovagal attack, and pregnancy-associated nausea. Moreover, there were 
1200

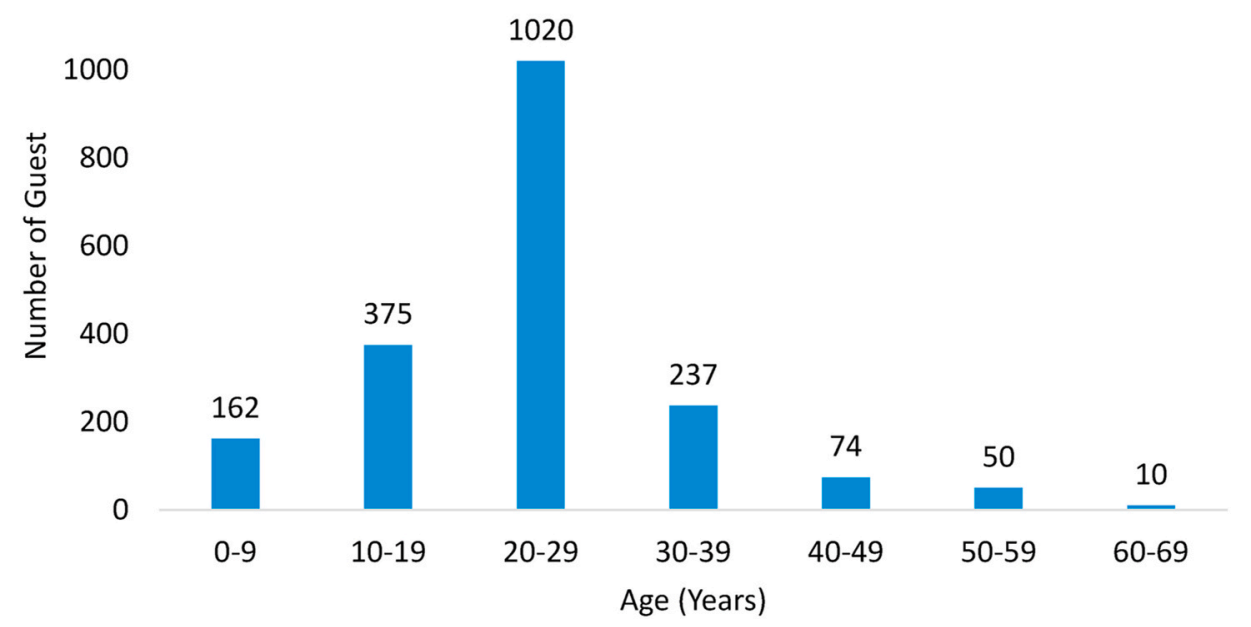

Fig. 4. A bar-graph showing the distribution of the age group of returning travelers.

Table 1

A summary of the results of the swabs of returning travelers.

\begin{tabular}{ll}
\hline Total Number of Guests & 1928 \\
\hline Gender & $66 \%$ Male 34\% Female \\
Age Range & 28 Days to 59 Years \\
Number of positive 1st Swab from all swabs & $14 / 1928(0.7 \%)$ \\
Number of positive 2nd swab from all swabs & September 1914 (0.5\%) \\
Number of any positive swab from all swabs & $23 / 1928(1.2 \%)$ \\
Number (\%) of admissions from the total & $40(2.1 \%)$ all admissions \\
1928 guests & $26(1.3 \%)$ for COVID-19 related \\
& issues \\
& $14(0.7 \%)$ for non-COVID-19 related \\
& issuses \\
\hline
\end{tabular}

instances of the occurrence of minor illnesses such as: gastroenteritis, vertigo, otitis externa, the need to adjust medications, epistaxis, and burn injuries. These minor issues were tackled by the medical team on the quarantine facilities with no need for hospital transfer.

\section{Discussion}

In this study, we described our experience with opening and running quarantine facilities for returning travelers who were hosted for COVID19 evaluation. The experience involved medical and non-medical care and highlighted the needed logistics. We had shown that the prevalence of COVID-19 among returning travelers to KSA and who were admitted to a quarantine facility was relatively low and was $1.2 \%$. The initial swabs gave a positivity rate of $0.7 \%$ among 1928 returning travelers. A previous study of 337 passengers, none of them tested positive at day 0 and day 5 [12]. The low rate of positive SARS-CoV-2 tests of returning travelers suggest that the strategy of 14-days quarantine needs to be

Table 2

Age Range and Incidence Rates (\%) of Positive Samples in each age group range (in years).

\begin{tabular}{llll}
\hline $\begin{array}{l}\text { Age } \\
\text { Range }\end{array}$ & $\begin{array}{l}\text { Number of } \\
\text { Guests }\end{array}$ & $\begin{array}{l}\text { Number (\%) 1st Swab } \\
\text { Positive }\end{array}$ & $\begin{array}{l}\text { Number (\%) 2nd Swab } \\
\text { Positive }\end{array}$ \\
\hline $0-9$ & 162 & $1(0.6)$ & $0(0)$ \\
$10-19$ & 375 & $3(0.8)$ & $1(0.3)$ \\
$20-29$ & 1020 & $3(0.3)$ & $5(0.5)$ \\
$30-39$ & 237 & $3(1.3)$ & $2(0.8)$ \\
$40-49$ & 74 & $3(4.1)$ & $1(1.4)$ \\
$50-59$ & 50 & $1(2)$ & $0(0)$ \\
$60-69$ & 10 & $0(0)$ & $0(0)$ \\
\hline
\end{tabular}

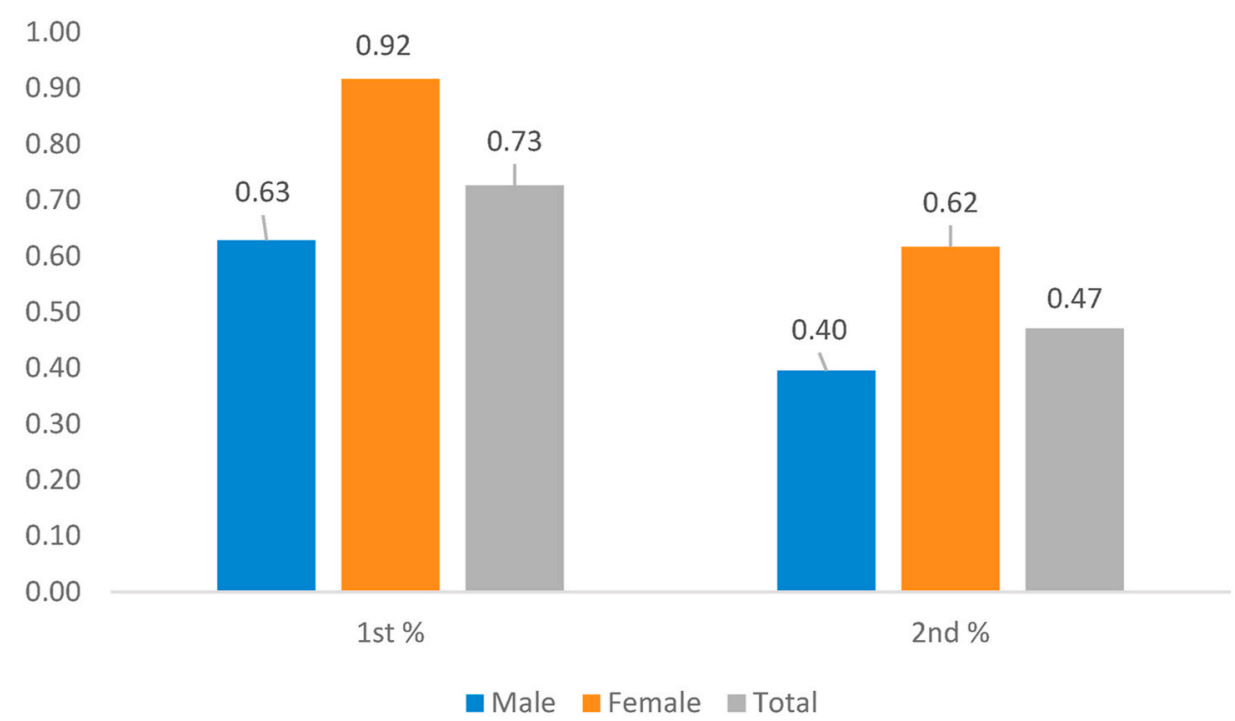

Fig. 5. The Positivity Rate of SARS-CoV-2 RT-PCR among Returning Travelers according to the 1st and 2nd Swab among males, females, and all travelers. 
Table 3

A summary of the Prevalence and Incidence of Positive RT-PCR for SARS-CoV-2 per week from the introduction of the Quarantine.

\begin{tabular}{|c|c|c|c|c|c|c|}
\hline $\begin{array}{l}\text { Weeks since Quarantine } \\
\text { Introduced }\end{array}$ & $\begin{array}{l}\text { Number of COVID- } \\
19 \text { Positive }\end{array}$ & $\begin{array}{l}\text { Total Travelers in } \\
\text { Quarantine }\end{array}$ & $\begin{array}{l}\text { Prevalence of } \\
\text { COVID-19 (\%) }\end{array}$ & $\begin{array}{l}\text { Number of new COVID-19 } \\
\text { infections in the specified week }\end{array}$ & $\begin{array}{l}\text { Number of New } \\
\text { Passengers }\end{array}$ & $\begin{array}{l}\text { Incidence of } \\
\text { COVID-19 (\%) }\end{array}$ \\
\hline 4 & 9 & 153 & 5.9 & 9 & 153 & 5.9 \\
\hline 5 & 13 & 294 & 4.4 & 4 & 141 & 2.8 \\
\hline 6 & 20 & 510 & 3.9 & 7 & 216 & 3.2 \\
\hline 7 & 23 & 1572 & 1.5 & 3 & 1062 & 0.28 \\
\hline 8 & 24 & 1572 & 1.5 & 1 & 0 & 1 \\
\hline 9 & 24 & 1678 & 1.4 & 0 & 106 & 0 \\
\hline 10 & 24 & 1740 & 1.4 & 0 & 62 & 0 \\
\hline 11 & 24 & 1740 & 1.4 & 0 & 0 & 0 \\
\hline 12 & 24 & 1740 & 1.4 & 0 & 0 & 0 \\
\hline 13 & 24 & 1929 & 1.2 & 0 & 189 & 0 \\
\hline
\end{tabular}

revisited. Travelers arriving KSA after May 7th, 2020 were allowed to complete one week of facility quarantine followed by an additional week of home quarantine, monitored by Mobile phone tracking to ensure compliance. In addition, the policy in KSA had changed to a seven-day quarantine for the general population and a three-day quarantine with a PCR test. Further enhancement of the protocol is being considered to include a laboratory-based strategy to rule out positive SARS-CoV-2 and away from a time-based strategy of 14-days quarantine. In addition, there are increased thoughts to have salivary SARS-CoV-2 test to facilitate travel. These tests could be done at the airport with a rapid turn-around-time of the salivary tests. Developing rapid point of care tests for SARS-CoV-2 would further enhance the ability of travelers to easily travel [13]. In a meta-analysis, SARS-CoV-2 saliva tests had a sensitivity of 91\% (CI 80-99\%) vs. 98\% (CI 89-100\%) for nasopharyngeal swab [14]. An additional point-of-care test could utilize SARS-CoV-2 antigen for travelers and currently approved devices give results in about $15 \mathrm{~min}$. However, antigen tests for SARS-CoV-2 are less sensitive than RT-PCR tests [15].

In this study, the majority of travelers where male with a 2:1 ratio, however, there was no statistical difference in the positivity rate between male and females. This finding is consistent with data that show no difference in the susceptibility to COVID-19 among males and females [16]. We observed that 9 travelers tested positive at day 12 of arrival and had initial negative 1st Swab. This is consistent with known incubation period of 2.1-11.1 days [17] and may represent the sensitivity of the PCR test of around 70\% from a single swab [18] or the presence of asymptomatic individuals who may had positive PCR test after the initial swab but were not detected till a repat swab was done at the end of the quarntine period [19].

The majority of patients had asymptomatic presentation (11/14; $79 \%)$ and those with symptoms $(3 / 14 ; 21 \%)$ only showed mild upper respiratory tract infection. It had been shown that asymptomatic SARSCoV-2 infection is variable and was $17 \%$ among household contacts [20], 17.4\% among children in a meta-analysis [21], and 10\% of 100 SARS-COV-2 patients in Taiwan [22]. In one study, asymptomatic patients were more likely to be present among those $<45$ years of age but could occur at any age [23].

The majority of positive cases in this study originated from the UK (93\%). This is likely secondary to the fact that the peak of UK cases occurred late April-early May 2020 and that the cases had not yet peaked in the other countries. The Quarantine began on March 6th, 2020 and in the 1st four weeks of the Quarantine the prevalence of COVID-19 positivity was $5.9 \%$. Then the incidence steady declined up to 8 weeks after the start of the Quarantine. After this time the prevalence became static at $1.4 \%$ with no new cases. This finding may reflect the benefits of worldwide lockdown measures coming into existence over this time period and possibly individuals taking more precautions at the country of travel as the disease became more prevalent. Early during the emergence of COVID-19 pandemic, travel-associated SARS-COV-2 infection was taken seriously across the globe. In Germany, COVID-19 outbreak was linked to a travelers from China [22]. In one study, one of $76(1.3 \%)$ quarantined travelers tested positive for SARS-CoV-2 [24]. The occurrence of travel-associated cases was coupled with enhanced contact screening in multiple countries such as the USA [25]. Thus, one important measure to delay the introduction of COVID-19 or any other newly emerging infectious disease to a country or area or to delay the peak of an epidemic in areas with local transmission is the application of quarantine measures early in an outbreak as suggested by the World Health Organization [26]. Thus, the Kingdom of Saudi Arabia took these measures early on in the COVID-19 pandemic. A similar strategy of mandatory 14-day quarantine for incoming travelers were implemented in Hong Kong for those coming from affected areas [26]. Subsequently, such measures were relaxed and now KSA requires a seven-day home quarantine for asymptomatic returning travelers. In a mathematical model, screening of travelers at port-of-entry utilizing clinical features as well as for those coming from COVID-19-affected countries has modest delay in the introduction of the SARS-CoV-2 into any community [27]. A meta-analysis showed that quarantine of exposed individuals prevented $44-81 \%$ incident cases and $31-63 \%$ of deaths compared to no measures and there was very low-certainty evidence suggesting earlier quarantine measures are associated with greater cost savings [27]. However, the meta-analysis did not address returning travelers per se.

Only $0.7 \%$ of travelers became unwell and required hospital admissions for non-COVID-19 related illnesses such as Diabetic Ketoacidois, appendicitis and foot fracture. This highlights the need to have access to medical care at any quarantine facility. We are fortunate to have all our guest as part of our electronic medical record and we were able to connect to these records. Other institutes may find this link of medical record challenging and requires contacting the primary care physicians or the healthcare providers with difficulty in such process [28] and thius may delay medical care.

In conclusion, this study showed the efforts put for establishing and managing facilities for quarantine and that such activity yielded a lower incidence of positive cases with increasing global cases. There was a need to have a backup healthcare facility to accommodate those developing medical needs for evaluation and admission for COVID-19 as well as non-COVID-19 related illnesses.

\section{Funding source}

There is no funding for this study.

\section{CRediT authorship contribution statement}

Jaffar A. Al-Tawfiq: Formal analysis, Data curation, Writing original draft, conceptual design, data analysis, drafted the first manuscript. Amar Sattar: Formal analysis, Data curation, Writing - original draft, data collection, data analysis, Helped with the first draft of the manuscript. Husain Al-Khadra: Formal analysis, Data curation, data collection, data analysis. Saeed Al-Qahtani: Formal analysis, Data curation, data collection, data analysis. Mobarak Al-Mulhim: Data curation, data collection, concept design. Omar Al-Omoush: Formal 
analysis, Data curation, data collection, data analysis. Hatim O. Kheir: Formal analysis, Data curation, Writing - original draft, data collection, data analysis. All authors finalized and approved the final draft of the manuscript.

\section{Declaration of competing interest}

The authors declare that they have no known competing financial interests or personal relationships that could have appeared to influence the work reported in this paper.

\section{References}

[1] Al-Tawfiq JA, Gautret P. Asymptomatic Middle East Respiratory Syndrome Coronavirus (MERS-CoV) infection: extent and implications for infection control: a systematic review. Trav Med Infect Dis 2019;27:27-32. https://doi.org/10.1016/j tmaid.2018.12.003.

[2] Al-Omari A, Alhuqbani WN, Zaidi ARZ, Al-Subaie MF, AlHindi AM, Abogosh AK, et al. Clinical characteristics of non-intensive care unit COVID-19 patients in Saudi Arabia: a descriptive cross-sectional study. J Infect Public Health 2020. https://doi. org/10.1016/j.jiph.2020.09.003.

[3] Al-Tawfiq JA, Memish ZA. COVID-19 in the eastern mediterranean region and Saudi Arabia: prevention and therapeutic strategies. Int J Antimicrob Agents 2020; 55. https://doi.org/10.1016/j.ijantimicag.2020.105968.

[4] Al-Tawfiq JA, Leonardi R, Fasoli G, Rigamonti D. Prevalence and fatality rates of COVID-19: what are the reasons for the wide variations worldwide? Trav Med Infect Dis 2020:101711. https://doi.org/10.1016/j.tmaid.2020.101711.

[5] Shi H, Han X, Jiang N, Cao Y, Alwalid O, Gu J, et al. Radiological findings from 81 patients with COVID-19 pneumonia in Wuhan, China: a descriptive study. Lance Infect Dis 2020;20:425-34. https://doi.org/10.1016/S1473-3099(20)30086-4.

[6] Gautret P, Al-Tawfiq JA, Hoang VT. Covid 19: will the 2020 hajj pilgrimage and tokyo olympic games be cancelled? Trav Med Infect Dis 2020:101622. https://doi org/10.1016/j.tmaid.2020.101622.

[7] Al-Tawfiq JA, Garout MA, Gautret P. Preparing for emerging respiratory pathogens such as SARS-CoV, MERS-CoV, and SARS-CoV-2. Le Infez Med 2020;28:64-70.

[8] Centers for Disease Control and Prevention CDC. Use of quarantine to prevent transmission of severe acute respiratory syndrome -Taiwan. Morb Mortal Wkly Rep 2003 2003;52:680-3. https://doi.org/10.1001/jama.290.8.1021.

[9] Saudi Ministry of Health. Middle East respiratory syndrome coronavirus 2018 guidelines for healthcare professionals. https://www.moh.gov.sa/CCC/health p/regulations/Documents/MERS-CoV Guidelines for Healthcare Professionals May 2018 - v5.1 \%281\%29.pdf. [Accessed 23 May 2019].

[10] [No authors listed]. Will your ED have staff quarantined for SARS? Brace yourself for the worst. ED Manage 2003:15:49-51. suppl 1.

[11] AlJishi JM, Al-Tawfiq JA. Intermittent viral shedding in respiratory samples of patients with SARS-CoV-2: observational analysis with infection control implications. J Hosp Infect 2020. https://doi.org/10.1016/j.jhin.2020.09.011.

[12] Lagier JC, Colson P, Tissot Dupont H, Salomon J, Doudier B, Aubry C, et al. Testing the repatriated for SARS-Cov2: should laboratory-based quarantine replace traditional quarantine? Trav Med Infect Dis 2020;34. https://doi.org/10.1016/j. tmaid.2020.101624.

[13] Paul R, Ostermann E, Wei Q. Advances in point-of-care nucleic acid extraction technologies for rapid diagnosis of human and plant diseases. Biosens Bioelectron 2020;169. https://doi.org/10.1016/j.bios.2020.112592.
[14] Czumbel LM, Kiss S, Farkas N, Mandel I, Hegyi A, Nagy Á, et al. Saliva as a candidate for COVID-19 diagnostic testing: a meta-analysis. Front Med 2020;7. https://doi.org/10.3389/fmed.2020.00465.

[15] Centers for Disease C. Interim guidance for rapid antigen testing for SARS-CoV-2 2020. https://www.cdc.gov/coronavirus/2019-ncov/lab/resources/antigen-te sts-guidelines.html. [Accessed 2 October 2020].

[16] Jin J-M, Bai P, He W, Wu F, Liu X-F, Han D-M, et al. Gender differences in patients with COVID-19: focus on severity and mortality. Front Public Heal 2020;8:152. https://doi.org/10.3389/fpubh.2020.00152.

[17] Backer JA, Klinkenberg D, Wallinga J. Incubation period of 2019 novel coronavirus (2019- nCoV) infections among travellers from Wuhan, China, 2028 January 2020. Euro Surveill 2020:25. https://doi.org/10.2807/1560-7917. ES.2020.25.5.2000062.

[18] Al-Tawfiq JA, Memish ZA. Diagnosis of SARS-CoV-2 infection based on CT scan vs. RT-PCR: reflecting on experience from MERS-CoV. J Hosp Infect 2020. https://doi. org/10.1016/j.jhin.2020.03.001.

[19] Al-Tawfiq JA. Asymptomatic coronavirus infection: MERS-CoV and SARS-CoV-2 (COVID-19). Trav Med Infect Dis 2020. https://doi.org/10.1016/j. tmaid.2020.101608.

[20] Yousaf AR, Duca LM, Chu V, Reses HE, Fajans M, Rabold EM, et al. A prospective cohort study in non-hospitalized household contacts with SARS-CoV-2 infection: symptom profiles and symptom change over time. Clin Infect Dis 2020. https://doi. org/10.1093/cid/ciaa1072.

[21] Ma X, Liu S, Chen L, Zhuang L, Zhang J, Xin Y. The clinical characteristics of pediatric inpatients with SARS-CoV-2 infection: a meta-analysis and systematic review. J Med Virol 2020. https://doi.org/10.1002/jmv.26208.

[22] Tsou T-PCW-CS-Ehacs-CCW-CS-EHASC-PTT-PLP-HCP-CWH-HHS-TSW-JSY-SWHYCM-YWP-YWK-CT. Epidemiology of the first 100 cases of COVID-19 in Taiwan and its implications on outbreak control. J Formos Med Assoc 2020. https://doi org /10.1016/j.jfma.2020.07.015.

[23] Yu C, Zhou M, Liu Y, Guo T, Ou C, Yang L, et al. Characteristics of asymptomatic COVID-19 infection and progression: a multicenter, retrospective study. Virulence 2020. https://doi.org/10.1080/21505594.2020.1802194. 21505594.2020.1802194.

[24] Ng OT, Marimuthu K, Chia PY, Koh V, Chiew CJ, de Wang L, et al. SARS-CoV-2 infection among travelers returning from Wuhan, China. N Engl J Med 2020;382: 1476-8. https://doi.org/10.1056/NEJMc2003100.

[25] Burke RM, Balter S, Barnes E, Barry V, Bartlett K, Beer KD, et al. Enhanced contact investigations for nine early travel-related cases of SARS-CoV-2 in the United States. MedRxiv 2020. https://doi.org/10.1101/2020.04.27.20081901. 2020.04.27.20081901.

[26] World Health Organization WHO. Considerations for quarantine of individuals in the context of containment for coronavirus disease (COVID-19) 2020 https://www.who. int/publications/i/item/considerations-for-quarantine-of-individuals-in-th e-context-of-containment-for-coronavirus-disease-(covid-19. [Accessed 31 July 2020].

[27] Mandal S, Bhatnagar T, Arinaminpathy N, Agarwal A, Chowdhury A, Murhekar M, et al. Prudent public health intervention strategies to control the coronavirus disease 2019 transmission in India: a mathematical model-based approach. Indian J Med Res 2020;151:190-9. https://doi.org/10.4103/ijmr.IJMR 504_20.

[28] Al-Busaidi IS, Martin M. Provision of primary care in managed isolation and quarantine facilities during the COVID-19 pandemic: lessons learned from Christchurch, New Zealand | OPEN ACCESS. N Z Med J 2020;133:130-2. 


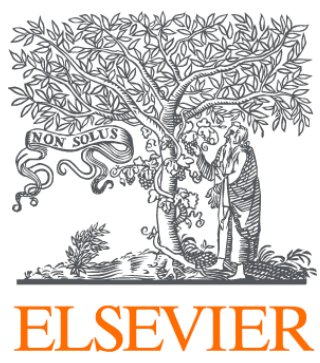

Since January 2020 Elsevier has created a COVID-19 resource centre with free information in English and Mandarin on the novel coronavirus COVID-

19. The COVID-19 resource centre is hosted on Elsevier Connect, the company's public news and information website.

Elsevier hereby grants permission to make all its COVID-19-related research that is available on the COVID-19 resource centre - including this research content - immediately available in PubMed Central and other publicly funded repositories, such as the WHO COVID database with rights for unrestricted research re-use and analyses in any form or by any means with acknowledgement of the original source. These permissions are granted for free by Elsevier for as long as the COVID-19 resource centre remains active. 